\title{
Massive Bone Marrow Carcinomatosis Presenting with Leukoerythroblastic Blood Reaction
}

\author{
Ana Garzo*, Verdu-Belmar J , Campos E, De Paz \\ FJ and Tarin F \\ General Hospital of Alicante, Spain \\ *Correspondling author: Ana Garzo, Pintor Baeza, $\mathrm{n}$ 은 \\ 11. 03010 Alicante, Spain
}

Received: February 18, 2021; Accepted: March 18, 2021; Published: March 25, 2021

\begin{abstract}
We present a case of an extensive bone marrow infiltrate of poorly differentiated carcinoma, in a 19-year-old male with suspected progression of sinusal undifferentiated carcinoma, after several lines of treatment.

Keywords: Massive bone marrow; Leukoerythroblastic blood; Carcinomatosis
\end{abstract}

\section{Clinical Image}

A 19-year-old male with a history of sinusal undifferentiated carcinoma was admitted for suspected progression after several lines of treatment, presenting severe bicytopenia $\left(19,000 \times 10^{3} / \mu \mathrm{L}\right.$ platelets and hemoglobin of $9.8 \mathrm{~g} / \mathrm{dL}$ ). A leukoerythroblastic blood picture was observed with immature myeloid forms and 20-30\% of erythroblasts, without atypical or blast cells. The bone marrow aspirate showed a great infiltration by polymorphic cells with numerous cytoplasmic blebs, that were organized in occasional syncytia and these findings did not suggest a hemopoietic population (Figure 1, panels A-C: Wright-Giemsa stain; 10x, 100x and 40x objective lens respectively) [1]. Diffuse bone marrow infiltration by neoplastic cells results in replacement of hematopoietic elements in the marrow.

Flow cytometry plots of those abnormal cells showed expression of CD56 and NG2, without expression for myeloid/monocytic antigens, erythroid/megakaryocytic antigens, lymphoid antigens, dendritic cells and stem cells. The study was compatible with medullary infiltration by extrahematological neoplasia of epithelial/ neuroepithelial origin $\mathrm{CD}^{+} 6^{+}\left(\mathrm{NCAM}^{+}\right)$and $\mathrm{NG}^{+}$. Pathologist interpretation revealed an extensive infiltrate of poorly differentiated carcinoma.

Bone marrow metastases usually present undifferentiated morphological characteristics and the diagnostic requires the integration of clinical manifestations, laboratory findings, morphology, flow cytometry, inmunohistochemistry techniques, cytogenetics and molecular biology [2,3]. The contribution of flow cytometry and pathologist interpretation was essential in this case.

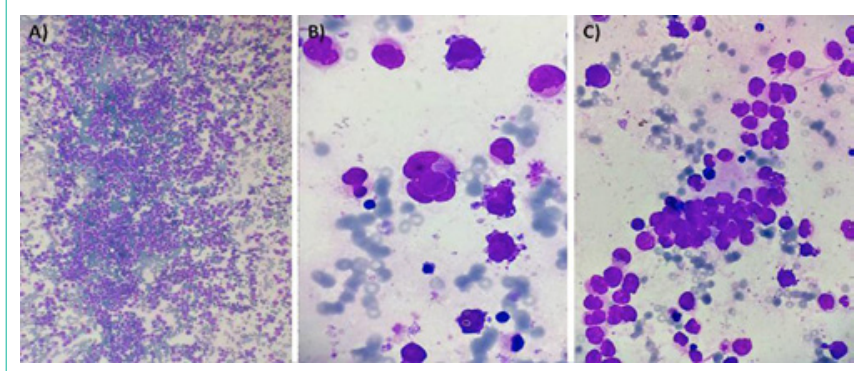

Figure 1: Hematoxylin/eosin (H\&E) staining of bone marrow aspirate in a case of a massive bone marrow poorly differentiated carcinomatosis. The picture shows a great infiltration by polymorphic cells (A) 10x magnification) with numerous cytoplasmic blebs (B) 100x magnification) and cohesive clusters of tumor cells (C) $50 x$ magnification).

\section{References}

1. Krzysztof Lewandowski \& Agnieszka Complak \& Andrzej Hellmann. Microscopic examination of bone marrow aspirates in malignant disorders of haematopoiesis-a comparison of two slide preparation techniques. Ann Hematol. 2012; 91: 497-505.

2. Syed NN, Moiz B, Adil SN, Khurshid M. Diagnostic importance of bone marrow examination in non-hematological disorders. J Pak Med Assoc. 2007; 57: $123-125$.

3. Ozkalemkas F, Ali R, Ozkocaman V, Ozcelik T, Ozan U, Ozturk H, et al. The bone marrow aspirate and biopsy in the diagnosis of unsuspected nonhematologic malignancy: A clinical study of 19 cases. BMC Cancer. 2005; 5: 144 .
Ann Hematol Oncol - Volume 8 Issue 3 - 2021 ISSN : 2375-7965 | www.austinpublishing group.com Garzo et al. ( ) All rights are reserved
Citation: Garzo A, Verdu-Belmar J, Campos E, De Paz FJ and Tarin F. Massive Bone Marrow Carcinomatosis Presenting with Leukoerythroblastic Blood Reaction. Ann Hematol Oncol. 2021; 8(3): 1336. 